\title{
A Probabilistic Neural Network Model for Lameness Detection
}

\author{
M. E. Pastell ${ }^{\star 1}$ and M. Kujala† \\ *Department of Agrotechnology, PO Box 28 (Koetilantie 3), and \\ †Faculty of Veterinary Medicine, PO Box 66, FI-00014 University of Helsinki, Finland
}

\begin{abstract}
A 4-balance system for measuring the leg-load distribution of dairy cows during milking to detect lameness was developed. Leg weights of 73 cows were successfully recorded during almost 10,000 robotic milkings over a period of 5 mo. Cows were scored weekly for locomotion, and lame cows were inspected clinically for hoof lesions. Unsuccessful measurements, caused by cows standing outside the balances, were removed from the data with a special algorithm, and the mean leg loads and number of kicks during milking were calculated. To develop an expert system to automatically detect lameness cases, a model was needed, and a classifying probabilistic neural network model was chosen for the task. The data were divided into 2 parts and 5,074 measurements from 37 cows were used to train a classifying probabilistic neural network model. The operation of the model was evaluated for its ability to detect lameness in the validating data set, which had 4,868 measurements from 36 cows. The model was able to classify $96.2 \%$ of the measurements correctly as sound or lame cows, and $100 \%$ of the lameness cases in the validation data were identified. The number of measurements (equal to the number of milkings) causing false alarms was $1.1 \%$. The model developed has the potential to be used as an on-farm decision aid and can be used in a real-time lameness monitoring system.
\end{abstract}

Key words: hoof disease, expert system, lameness detection, automatic health monitoring

\section{INTRODUCTION}

Lameness is a crucial welfare issue in modern dairy husbandry. Limb disorders cause serious welfare, health, and economic problems, especially in the loose housing of cattle (Juarez et al., 2003; Klaas et al., 2003). Lameness causes losses in milk production (Warnick et al., 2001; Green et al., 2002) and leads to early culling

Received May 4, 2006.

Accepted January 19, 2007.

${ }^{1}$ Corresponding author: matti.pastell@helsinki.fi
(Enting et al., 1997). These costs could be reduced with early identification and treatment.

Only a few existing technological methods exist to detect the leg problems of dairy cows. Rajkondawar et al. (2002) developed a walk-through system for lameness detection. The system identified affected limbs by measuring the ground reaction forces. Tasch and Rajkondawar (2004) also further developed the SoftSeparator algorithm to separate measurements of a group of cows that walked through the system, and Rajkondawar et al. (2006) further developed models to identify lame cows. This enabled use of the system, for example, when the cows exited the milking parlor. In addition, machine vision-based gait analysis with image processing software (Flower et al., 2005) and resampling condensation with hidden Markov models (Magee and Boyle, 2002) have been used to detect lameness in dairy cows.

We developed a 4-balance system for identifying leg problems in a milking robot. The system has shown the capability to detect leg problems from changes in dynamic leg loads, as well as step and kick behavior during milking (Pastell et al., 2006). Software for continuous data acquisition and algorithms for data processing and automatic alarms of leg problems have been developed (Pastell et al., 2005). The problem with the system was that it gave too many false alarms. Therefore, a model was needed to classify the cows into lame and sound groups.

The development of artificial neural networks was inspired by the human brain, and the first practical applications were introduced in the 1950s. Since then, they have found numerous practical applications in many different fields (Hagan et al., 1997). Neural networks are used for solving problems where input and output values are known, but it is difficult to translate the relationship into a mathematical representation (Visen et al., 2002).

A probabilistic neural network (PNN) is an artificial neural network that is used for data classification tasks (Specht, 1990). Applications include pig cough recognition (Chedad et al., 2001), clinical diagnosis of cancer (Shan et al., 2002), a predictive classifier for hospital defibrillation outcomes (Yang et al., 2005), and cereal 


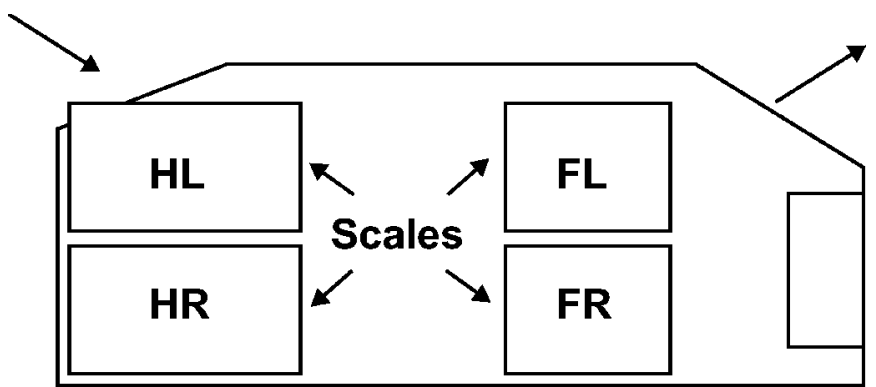

ROBOTIC ARM

Figure 1. Balance platforms in the floor of the milking robot. FL = front left; $\mathrm{FR}=$ front right; HL = hind left; HR = hind right.

grain classification (Visen et al., 2002). The advantage of the PNN models is that they usually outperform traditional statistical classifiers in nonlinear problems.

The aim of this study was to develop a PNN model for lameness detection based on the leg load data acquired with a 4-balance system. Characteristics of the measurement system and measured data, along with veterinary diagnoses, are described. This paper focuses on the preprocessing of the data, selected model inputs, and training and validation of the model.

\section{MATERIALS AND METHODS}

\section{Measurements}

The study was conducted on the University of Helsinki research farm in an insulated free-stall barn equipped with a DeLaval (Tumba, Sweden) voluntary milking system. The farm has 2 milking robots, but only one was used in the study. The cows milked with each robot were milked in separate groups. One group of 40 to 45 cows used in the study was milked by the robot during the measurement period. Because the cows were sometimes transferred from one milking group to another, we were able to follow a total of 73 cows with the system. The study was conducted in 2004 between June 15 and September 17, and between October 20 and December 7. Data between the 2 periods were missed because of technical difficulties. The free-stall barn in which cows were housed had a hard, slatted floor with scrapers in the manure alley and rubber mats in the free stalls. Alleys were $2 \mathrm{~m}$ wide, with one beside the feeding area and another in between stalls.

A 4-balance system was developed to measure the dynamic load of each leg separately during milking. The system consisted of 4 balance platforms (Figure 1), which were positioned in the floor of the milking robot in such a way that the dynamic load of each leg was measured (Pastell et al., 2006). Cows entered the stall from the left side of the robot and were milked from the right side. Each platform consisted of a plywood plate on top of a metal plate attached to a single-point load cell (1510, Vishay Tedea-Huntleigh, Chatsworth, $\mathrm{CA})$. The size of the platforms ranged from $445 \times 390$ $\mathrm{mm}$ to $310 \times 310 \mathrm{~mm}$ depending on the location. Platforms under the hind legs were larger than those under the front legs because we found that the placement of hind legs varied more between cows and milkings. The load cells were connected to a carrier frequency amplifier, and recorded data were transferred to a personal computer.

Leg weights measured during each milking were recorded automatically from the load cells using measurement software made with TestPoint (Capitol Equipment, Middleborough, MA). The measurement rate was set to $10 \mathrm{~Hz}$ to properly measure the weight change during kicking, because the duration of one kick was as short as $0.5 \mathrm{~s}$. The starting and stopping of measurements were based on information obtained from a log file created by a special program, which was provided by DeLaval and operated on the computer of the robot. The file was saved on the measurement computer's hard disk over a network created between the 2 computers and was read there with the measurement software. The log file contained cow identification in the robot and information about the action of the robot at that moment. The actions included milking, feeding, washing (the robot), and idling (Pastell et al., 2006). Leg weights were successfully recorded from almost 10,000 milkings of a total of 73 different cows.

Not all the measurements were obtained successfully because of cows standing outside the platforms. Young and small cows proved to be problematic. A cow standing outside the balances resulted in erroneous data that could not be used in health monitoring. Erroneous values were automatically removed from the data with a special algorithm. If less than $90 \mathrm{~s}$ of the original measurement remained after removing the erroneous values, the whole set of measurements was discarded from further analysis (Pastell et al., 2005). After removing the erroneous data, a total of 9,942 measurements remained for model development.

\section{Lameness Assessment and Clinical Inspections}

All cows were observed weekly for lameness during a normal gait by experienced personnel. A locomotion scoring system (Sprecher et al., 1997) was used during the visual inspections. The cows that scored at least 2 during the weekly inspections were then inspected clinically for hoof problems during hoof trimming. In addition, all cows that were at risk ( 2 to 5 mo in milk), all primiparous cows, and cows that showed symptoms 
Table 1. Scoring system for hoof pathologies identified during the study

\begin{tabular}{lcl}
\hline Lesion & Severity & \\
\hline Hemorrhages $^{1}$ & 0 & No hemorrhages or slight hemorrhages for small area in a single hoof \\
& 1 & Slight hemorrhages for large area or moderate hemorrhages for small or large area in multiple hooves \\
White-line problems & 2 & Severe or very severe hemorrhages in the hoof \\
& 0 & No problem \\
Sole ulcers & 1 & Mild problem \\
& 2 & Severe problem \\
Interdigital phlegmon & 0 & No problem \\
& 1 & Mild problem \\
& 2 & Severe problem \\
& 1 & No problem \\
& 2 & Sild problem \\
\hline
\end{tabular}

${ }^{1}$ Adapted from Bergsten (1993).

of lameness based on the leg weight measurements were examined clinically every $3 \mathrm{wk}$. In total, we observed 16 lameness cases caused by hoof problems in 15 cows and 2 lameness cases resulting from injuries in 2 other cows. All lameness problems detected during the study were in the hind legs. The protocol used in scoring hoof lesions was that used nationally by Finnish hoof trimmers and consisted of 9 different lesion scores (Kujala et al., 2004). Hemorrhages, sole ulcers, and white-line problems were scored more accurately, and they were also described verbally. If a sole was off, it was recorded separately in addition to the problem involved (e.g., bad white-line disease). The protocol used for scoring hoof pathologies identified during the study is shown in Table 1.

\section{Classification of Data}

Each of the measurements in the study was classified as sound or lame based on the gait scores and clinical inspections. Measurements were classified as sound when the cow had a gait score of 1 or 2 and no clinical problems were found. Measurements were classified as lame when the gait score was at least 3 or when serious clinical problems were found. The beginning of lameness was assessed from the weight curves. The help of weight curves was needed because lameness was not assessed daily by the observers. This also meant that the beginning of lameness in the data was not necessarily the same as the beginning of clinical lameness, because we could not be sure exactly when the clinical lameness started.

\section{Data Preprocessing}

After correcting the data, the average weight of each leg, standard deviation of the weight of each leg, total weight, number of kicks and steps, and frequency (times/minute) of kicks and steps were calculated for each weighing (equal to the number of milkings). A kick was described as a lifting of the leg in the air and was calculated when the weight of a leg decreased to less than $5 \mathrm{~kg}$ (drifting sometimes moved the zero level to $5 \mathrm{~kg}$ ), and a step was described as weight shifting and was calculated when the weight of a leg decreased to between 5 and $20 \mathrm{~kg}$. Steps and kicks can be seen as sharp peaks in the results. Data analyses are described in more detail elsewhere (Pastell et al., 2005, 2006).

Because all leg problems that were identified during this study were in the hind legs, we focused on analyzing the weight data from hind legs. To handle the leg problems in both hind legs in the same model, a leg weight ratio (LWR) between the lighter and heavier hind leg was calculated for each weighing.

$$
\text { LWR }=\frac{\text { lighter hind leg }}{\text { heavier hind leg }} \times 100 \% .
$$

Results from leg weights were divided into 2 classes, lame (443 measurements from 17 cows and 18 lameness cases) and sound (9,499 measurements from 72 cows), as described in the lameness assessment. We were able to assess measurements from 16 of 17 lame cows during a period when they were not lame. Therefore, measurements in those 16 cows exist in both data sets (sound and lame), resulting in a total of 73 cows (Table 2).

Measurements were divided into 2 groups with data from different cows for model development and validation. The teaching data set consisted of data from 37 cows and the validation data set consisted of data from 36 different cows. The number of measurements used in teaching was 5,074, with 4,868 for validation. Both data sets consisted of measurements from 9 lameness cases, and they both consisted of data from several primiparous and multiparous cows. From the cows in the validation data set, 7 were diagnosed as lame at some point during the study and one of the cows was diagnosed as lame during 2 separate time periods. 
Table 2. Numbers of cows and observations used for model teaching and validation

\begin{tabular}{lccccccc}
\hline & & & & & & \multicolumn{3}{c}{ Observations, no. } \\
\cline { 6 - 8 } Data set & Cows & $\begin{array}{c}\text { Sound } \\
\text { cows }\end{array}$ & $\begin{array}{c}\text { Lame } \\
\text { cows }\end{array}$ & $\begin{array}{c}\text { Lameness } \\
\text { cases }\end{array}$ & Total & $\begin{array}{c}\text { Sound } \\
\text { cows }\end{array}$ & $\begin{array}{c}\text { Lame } \\
\text { cows }\end{array}$ \\
\hline Teaching & 37 & $36^{1}$ & $9^{1}$ & 9 & 5,074 & 4,790 & 284 \\
Validation & 36 & $36^{1}$ & $8^{1}$ & 9 & 4,868 & 4,709 & 159 \\
Total & 73 & 72 & 17 & 18 & 9,942 & 9,499 & 443 \\
\hline
\end{tabular}

${ }^{1}$ Eight cows were healthy or lame during different periods of the study.

\section{Model Development and Validation}

A PNN model was chosen to solve the problem of classifying cows into lame and sound groups based on the measurements obtained. A PNN is an artificial neural network used for classification tasks (Chedad et al., 2001; Yang et al., 2005). The model was first taught with a teaching data set, which consisted of measurements along with the correct classification. When a new input vector (LWR and kicks per milking) was presented, the network classified it based on the information found in the teaching data set. The network consisted of 2 layers. The first layer, a radial basis layer, computed Euclidean weighted distances from a new input vector to the input training vectors and produced a new vector that indicated how close the input was to training inputs. The behavior of the model was adjusted by changing a model parameter referred to as "spread." With spread values close to zero, the network would act as a nearest neighbor classifier, but with larger values, the designed network took into account several nearby design vectors in the classification process. The second layer, a competitive layer, totaled the distance to each class and produced a net output vector of probabilities. After the summing, a complete transfer function applied to the net output vector selected the class with the greatest probability and classified the input to that class. This is illustrated in Figure 2.

Selection of the parameters used as model inputs was done by testing the performance of the model with all parameters described in data preprocessing and also combinations of these different parameters. Finally, LWR together with the number of kicks per milking were selected as the model inputs, because they were found to differentiate the lame cows from sound cows most accurately. The neural network toolbox of Matlab (Mathworks, Natick, MA) was used to develop and validate the model. The PNN was taught with the teaching data set using several spread values. The spread value is included as a parameter in the Matlab function.

The model taught with several spread values was validated with a data set independent from the teaching data. Each of the measurements in the validation data set was classified with the model. The model gave a classification as sound or lame for each of the measurements from every cow in the validation data. In a practical application, 2 or 3 classifications were made each day. Because we used only 2 classes (i.e., sound and lame) for the measurements, the model had only 2 possible outputs: sound or lame.

Performance of the PNN in the classification task was evaluated with the following criteria: 1) detection rate $=$ percentage of lameness cases in the validation data detected with the network; 2) percentage of measurements causing false alarms (i.e., percentage of measurements coming from sound cows classified as lame); 3) relative earliness of detection $=$ detection date with the model - the earliest classification date; 4) percentage of the measurements classified correctly as compared with the lameness assessment from locomotion scores; and 5) sensitivity and specificity of the model on a cow level.

\section{RESULTS}

During the veterinary inspections, a total of 18 lameness cases were found in 17 cows. Of those cases, 16

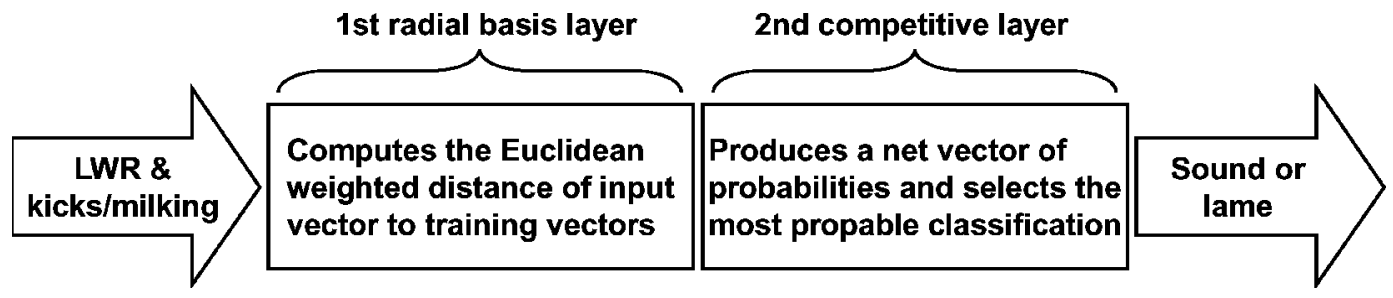

Figure 2. Operation of the PNN (probabilistic neural network) model. LWR = leg weight ratio between the heavier and lighter hind leg. 
Table 3. Characteristics of measurement data for sound and lame cows

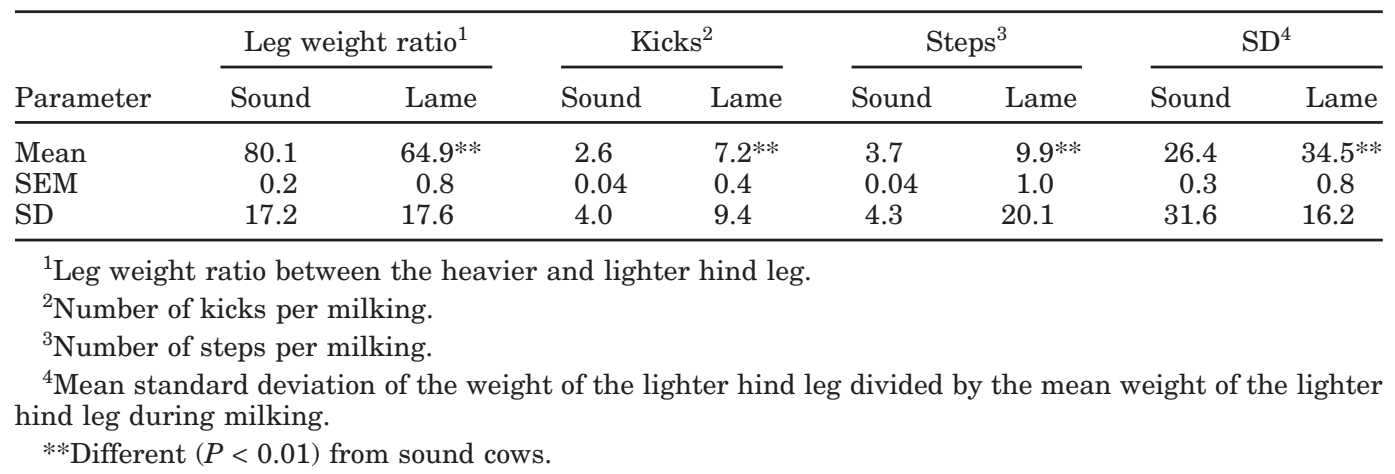

resulted from hoof problems and 2 from injuries. Observed hoof diseases were 7 white-line diseases, 8 sole ulcers, and one tyloma with interdigital phlegmon. All the sole ulcers were located in the sole bulb junction of the lateral claw. The white separations were mostly situated in the abaxial wall-bulb junction of the lateral claw and some were in the abaxial white zone of the lateral claw. The mean duration of lameness was 13.7 $\mathrm{d}$, with a standard deviation of $9 \mathrm{~d}$. This does not necessarily represent the actual duration of the problem, but rather the time the cow was milked by the robot used in the study. In some cases, cows were moved away from the robot, and some problems also overlapped with the break in the research period. All the observed cases were cured during the study. Included also were data from the sound period for 16 of 17 cows that were found lame at some point. Duration of the sound period ranged from $10 \mathrm{~d}$ to $5 \mathrm{mo}$.

The measurements of LWR (\%), standard deviation of the weight (\%) of the lighter hind leg during milking, kicks per milking, and steps per milking assessed in sound $(\mathrm{n}=9,499)$ and lame $(\mathrm{n}=443)$ cows are shown in Table 3. A difference $(P<0.01)$ was detected between lame and sound cows according to the Mann-Whitney $U$-test for all measurements. Despite clear statistical differences in the medians, the standard deviations indicated that distributions of all values assessed for sound and lame cows also overlapped, and no value alone allowed us to judge whether a cow was sound or lame. This is also why the PNN model was needed to classify the cows as lame or sound.

The change in weight distribution and step-kick frequency of the hind legs of one cow during an interdigital phlegmon is shown in Figure 3. Figure 3A shows the leg weights during milking when the cow is still sound, and Figure 3B-3D illustrates leg weights at different degrees of lameness. The disease progressed to severe lameness in only a few days. During the mild stage, the cow started to place less weight on the affected leg (Figure 3B). When the disease progressed to a more painful stage, the cow constantly lifted the affected leg to relieve the pain, which can be seen as frequent peaks in Figure 3C. During the most severe stage, the cow had a locomotion score of 4 and was removed from the robotic milking system and quarantined in a separate pen. The cow barely kept any weight on the affected limb and constantly lifted the leg (Figure 3D). The time difference between the 3 weights was only $2 \mathrm{~d}$. After the disease was treated, leg weights returned to normal (Figure 3E). Lameness also affected total BW of the cow before, during, and after lameness (Figure 3F). Total BW clearly decreased during lameness, but returned to prior values after the disease was cured.

The LWR, as a function of kicks per milking of the same cow, as in Figure 3, during a 1.5-mo period, is shown in Figure 4. The cow was either lame or sound during the research period, and a clear difference in the health status was observed. The LWR was less $(P$ $<0.001$ ) when the cow was lame because the cow placed less weight on the affected leg. The kicking frequency also was increased $(P<0.05)$ during lameness because the cow apparently relieved pain by lifting the affected leg. During the sound period, the weight of the cow was distributed quite evenly on both hind legs and the kicking frequency was rather low.

The effect of spread on the classifying ability of the model is shown in Figure 5. We decided that the model should achieve the best possible detection rate (i.e., all lameness cases should be identified, with the smallest possible number of false alarms). Figure 5 shows that the best performance was achieved with a spread of 0.8 . With that spread value, the overall classifying ability of the model was $96.2 \%$. The lameness detection rate was $100 \%$ and the number of measurements causing false alarms was $1.1 \%$. Some of the measurements classified lame cows as sound, but this did not decrease the detection rate because all the cows that were lame gave an alarm during the lame period. With spread values of $>0.8$, the detection rate decreased. With a detection 

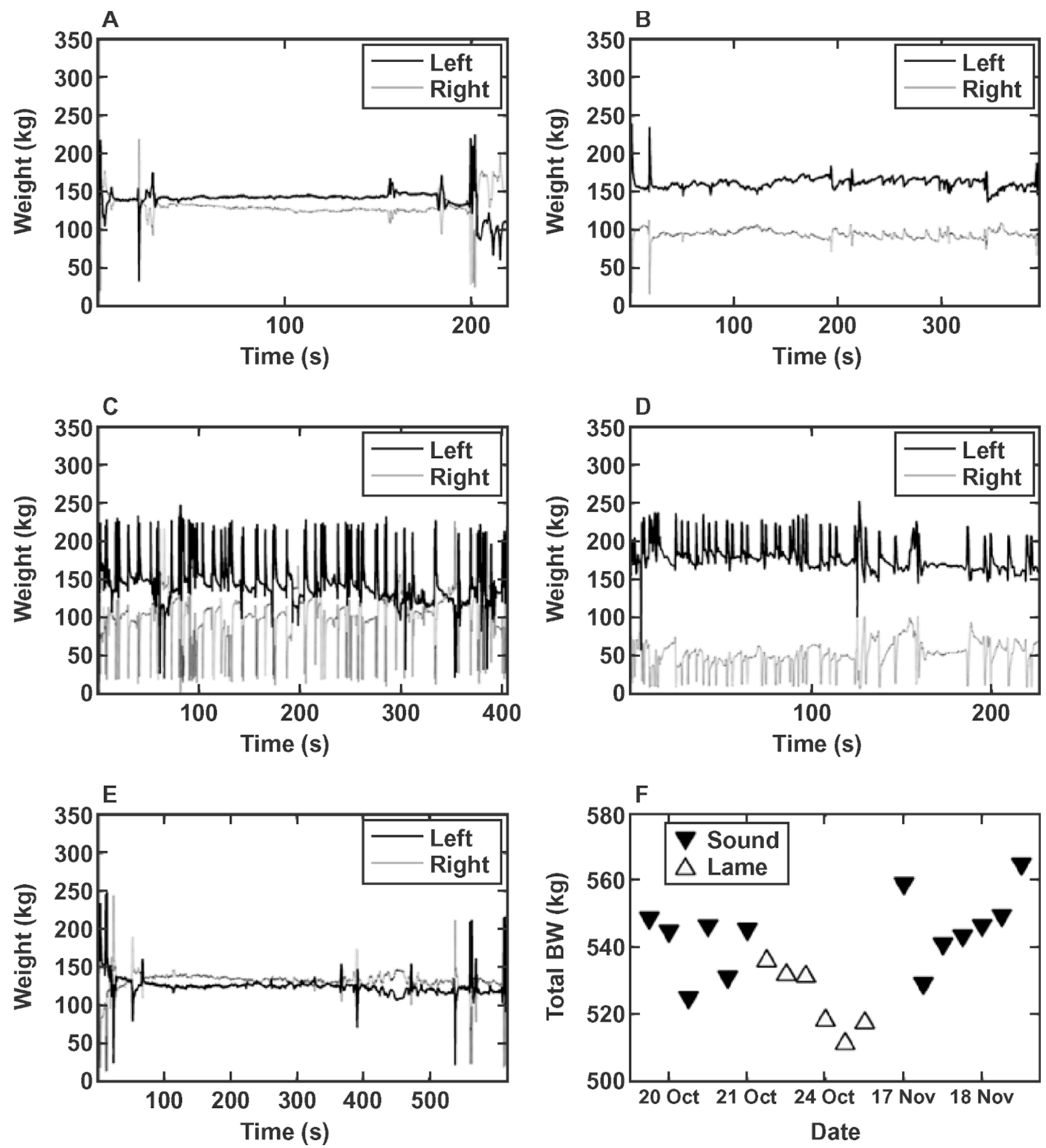

Figure 3. Weight on the hind legs of a cow during different health states: A) before lameness; B) early stage of lameness; C) severe lameness; D) even more severe lameness; E) after lameness. Change in the total BW (F) of the same cow before, during, and after lameness. 


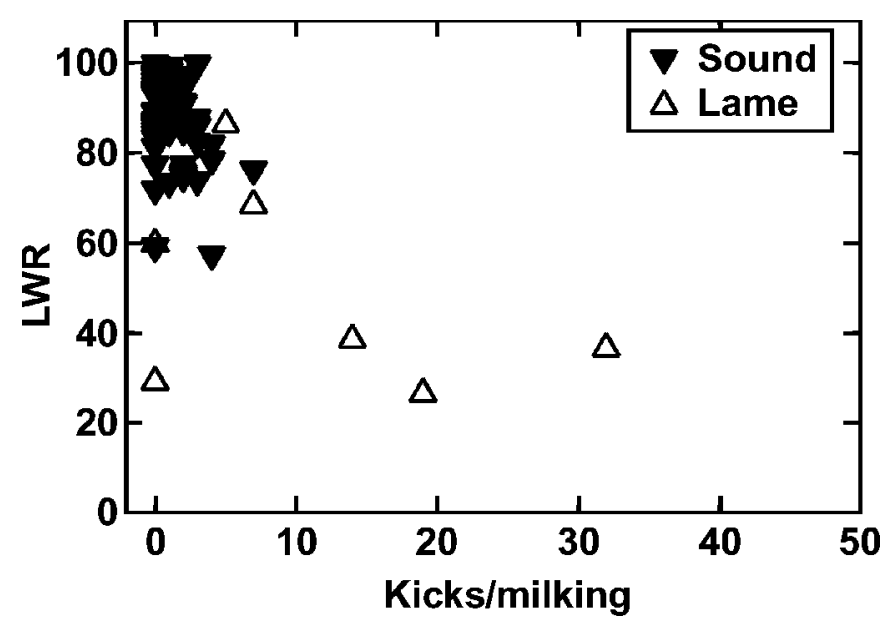

Figure 4. The leg weight ratio (LWR) between the heavier and lighter hind leg as a function of kicks per milking for one cow while sound or lame.

rate of $50 \%$, the number of measurements causing false alarms was only $0.08 \%$.

The effectiveness of the model in detecting lameness was evaluated with the help of a receiver operating characteristic (ROC) curve. Figure 6 shows the ROC curve for the test with different spread levels. The curve was created by calculating the sensitivity and specificity of the model classifications during the entire research period for individual cows in the validation data. This differs from Figure 5, in which the classification accuracy is evaluated for each measurement. The curve shows that with a sensitivity of $100 \%, 42.5 \%$ of cows

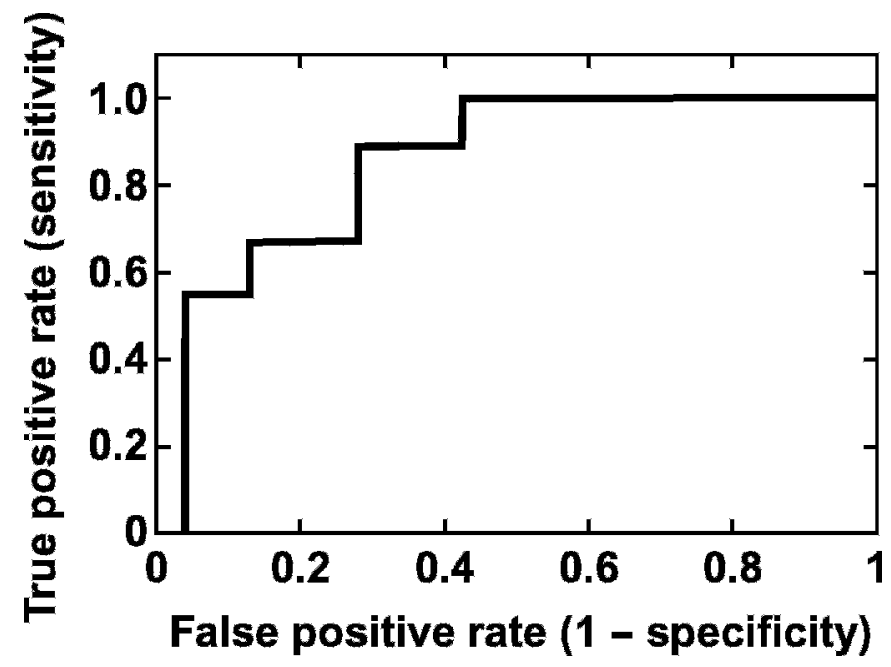

Figure 6. The receiver operating characteristic curve showing model performance as a diagnostic test for detecting lameness (area under the curve $=0.86$ ).

had still caused at least one false alarm in 5 mo. This means that even though only $1.1 \%$ of measurements gave false alarms, those measurements were taken from many different cows. The area under the curve (AUC) was 0.86.

In addition, we examined the relative earliness of alarms having different spread values. The time of problem identification with the PNN was compared with the time when cows in the validation set were first classified as lame, based on the weekly visual observations and veterinary records from clinical inspections.

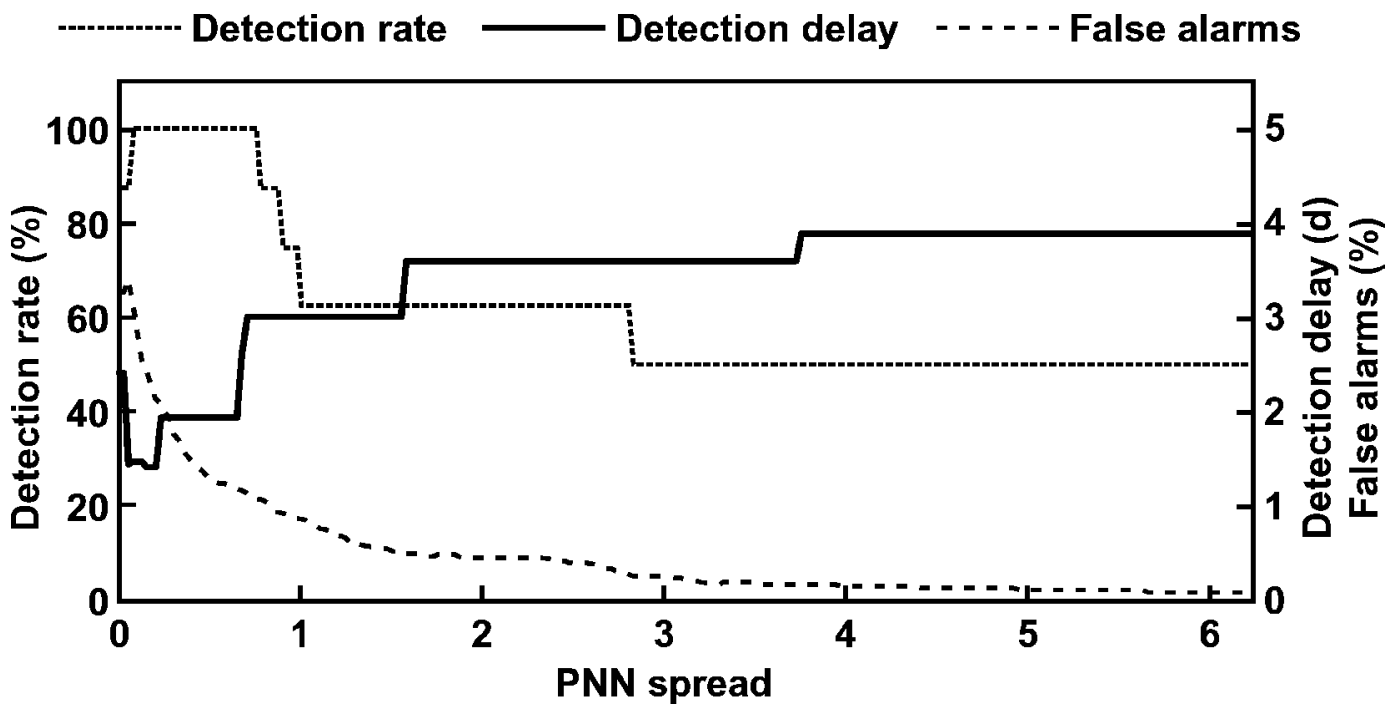

Figure 5. Effect of the PNN (probabilistic neural network) spread in the lameness detection rate, detection delay, and number of measurements causing false alarms. 


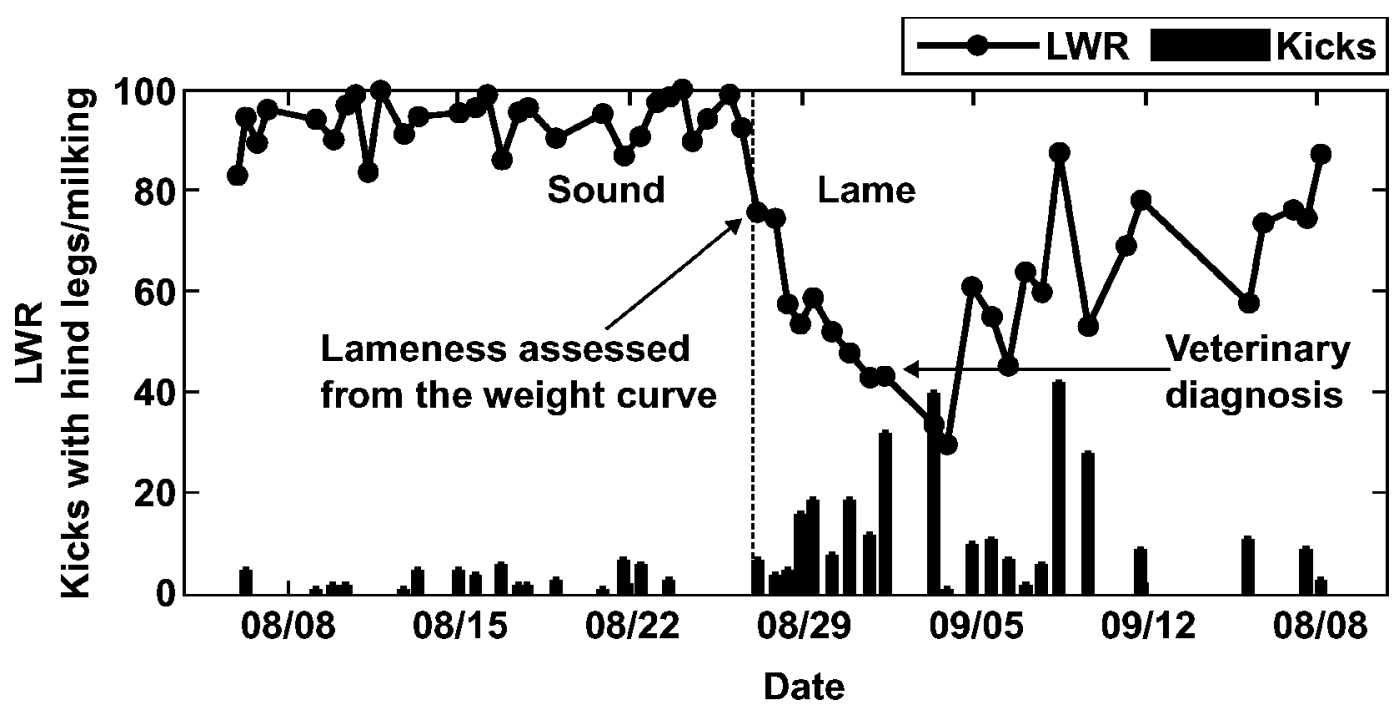

Figure 7. Lameness classification assessed from the weight curve. In the left panel, the cow was classified as sound, and in the right panel, the cow was lame. The leg weight ratio (LWR) is between the heavier and lighter hind leg.

The exact starting time was based on weight curves. An example of lameness assessment from the weight curves is shown in Figure 7. The arrows in the figure show the time when the cow was judged as lame from the curve and when the actual diagnosis took place. The cow suffered from lameness because of an injury involving the left hip and had a locomotion score of 5 .

The time difference between the first classification of lameness and detection with the model was called the relative detection delay. Average detection delays for 9 cows having different PNN spread values and detection rates are shown in Figure 5. One can see that increased spread, which also meant more reliable detection, led to delayed identification of lameness. Variation also occurred in the detection delay with the optimal detection rate. The figure clearly shows that there is a tradeoff situation between the time of first detection and the reliability of that detection.

\section{DISCUSSION}

The 4-balance system proved to be useful for identifying lameness in past studies (Pastell et al., 2005, 2006), but the number of false alarms was too great for the system to be used in automated detection. In this research, a PNN model for lameness detection was developed from the data acquired with the system. Information from 73 cows was divided into 2 parts for teaching and validating the model. We discovered that the spread value used in the model had a large effect on the detection rate and number of false alarms. With the optimal spread value of 0.8 , we achieved a detection rate of $100 \%$, with only $1.1 \%$ false alarms.
The performance of the model as a diagnostic test was evaluated with the help of a ROC curve. The AUC was 0.86 , which means the test is considered good in separating lame cows from sound cows. With the sensitivity of $100 \%$, a specificity of $57.5 \%$ was achieved. The sensitivity and specificity describe the proportion of cows classified correctly as sound or lame during the entire 5-mo research period. This means that when a cow gave a single false alarm during the entire period, it decreased the specificity of the test. However, if the system was used as an on-farm lameness assessment test, an occasional false alarm would not be that harmful as long as the system could find all the actual problems. The alarm is not meant to be an incentive to start treatment, but rather to alert the farmer to the cow in question so that the farmer can then decide what action to take.

Information on model behavior with different spread values can be used when on-farm use of the system is being considered. The system can judge each weighing by using several spread values and can provide alarms of differing priorities. Alarms given with small spread values indicate possible leg problems, whereas alarms with larger spread values indicate almost certain cases of lameness. On-farm use of the system could significantly improve identification of lameness cases, because results from Whay et al. (2003) suggested that dairy farmers fail to recognize $75 \%$ of all lameness cases.

We believe that the measurement system and model developed can be transferred to on-farm applications and also that it can work on other farms with singlestall milking robots. However, performance of the model 
must be validated with more cows and other farms. It is also possible to adapt the model with more data. Acquiring measurements from infectious hoof diseases and incorporating those into the model could be beneficial. Future work also should involve clinical inspection of cows that are not lame to identify all hoof lesions and their effect on the model.

Only a few methods for automated lameness detection have been developed. Rajkondawar et al. (2002, 2006) were able to successfully separate sound cows from lame cows with their walk-through system. They also developed gait- and lesion-based statistical models to detect lame cows and evaluated the performance of the models with ROC curves. They were able to obtain an AUC of 0.84 in their best case. Flower et al. (2005) were able to identify cows with sole ulcers by analyzing stride variables from video recordings. However, they had to use reflective markers on the legs of the cows and manually digitize the recordings, so the system was not adapted for automated lameness detection.

For farms with milking robots, we think that a 4balance system may be more suitable than a walkthrough system (Rajkondawar et al., 2002, 2006) or image analysis (Flower et al., 2005), because barns designed for automatic milking do not necessarily have suitable areas for gait measurements. With the current model, however, use of a 4-balance system is limited to farms having milking robots. It also could be used in automatic feeding systems, as supported by the findings of Neveux et al. (2006), who also used a system measuring the leg weight and found that discomfort under a hoof caused a cow to place less weight on the affected leg. Feeding systems, however, probably require a different model because cow behavior is different from that with a milking robot. Others (Van der Tol et al., 2004; Carvalho et al., 2005) measured the pressure on different parts of the hoof with pressure-sensitive sensors to observe the effects of hoof trimming on the weight balance under the hoof. However, neither of those reports indicated the use of their system in lameness detection.

One major advantage of this system is that it is observer independent and the results are repeatable. Several studies have shown that gait scoring, which is a common method used to assess lameness, is subjective. O'Callaghan et al. (2003) reported that the intraobserver repeatability in gait scoring for a 5-point numerical scoring system was only $56 \%$ and the interobserver repeatability was only $37 \%$. When a 1-point difference was allowed, however, the scores were in agreement for 93 and $81 \%$ of the scores, respectively. Winckler and Willen (2001) found a 68\% repeatability of scores among 3 observers. Flower and Weary (2006) were able to differentiate 22 of 24 cows with sole ulcers from sound cows by using a 5-point numerical rating system and an overall visual score. They also found that apparently sound cows had an average gait score of 3.1. A 4-balance system also collects leg health data automatically, which allows multiple daily observations for each cow.

In addition, the development and healing of hoof diseases and injuries as well as the effect of hoof treatment and medication can be detected as the condition of the cow changes. This makes it possible to use the system when evaluating the effect of treatments or when studying the development of different diseases.

\section{CONCLUSIONS}

A 4-balance system can be used for automatic lameness detection with the PNN model developed. The model was able to detect all leg problems in the validation data, with only $1.1 \%$ of false alarms given. The system has the potential to be used as an on-farm lameness identification tool in herds milked with an automatic milking system. The system also can be used to follow disease development and the effect of treatment on pain and healing.

\section{ACKNOWLEDGMENT}

The authors thank the Finnish Ministry of Agriculture for financing this project.

\section{REFERENCES}

Bergsten, C. 1993. A photometric method for recording hoof diseases in cattle, with special reference to haemorrhages of the sole. Acta Vet. Scand. 34:281-286.

Carvalho, V. R. C., R. A. Bucklin, J. K. Shearer, and L. Shearer. 2005. Effects of trimming on dairy cattle hoof weight bearing and pressure distributions during stance phase. Trans. ASAE 48:1653-1659.

Chedad, A., D. Moshou, J. M. Aerts, A. Van Hirtum, H. Ramon, and D. Berckmans. 2001. Recognition system for pig cough based on probabilistic neural networks. J. Agric. Eng. Res. 79:449-457.

Enting, H., D. Kooij, A. A. Dijkhuizen, R. B. M. Huirne, and E. N. Noordhuizen-Stassen. 1997. Economic losses due to clinical lameness in dairy cattle. Livest. Prod. Sci. 49:259-267.

Flower, F. C., D. J. Sanderson, and D. M. Weary. 2005. Hoof pathologies influence kinematic measures of dairy cow gait. J. Dairy Sci. 88:3166-3173.

Flower, F. C., and D. M. Weary. 2006. Effect of hoof pathologies on subjective assessments of dairy cow gait. J. Dairy Sci. 89:139-146.

Green, L. E., V. J. Hedges, Y. H. Schukken, R. W. Blowey, and A. J. Packington. 2002. The impact of clinical lameness on the milk yield of dairy cows. J. Dairy Sci. 85:2250-2256.

Hagan, M. T., H. B. Demuth, and M. Beale. 1997. Neural Network Design. PWS Publishing, Boston, MA.

Juarez, S. T., P. H. Robinson, E. J. DePeters, and E. O. Price. 2003. Impact of lameness on behaviour and productivity of lactating Holstein cows. Appl. Anim. Behav. Sci. 83:1-14.

Klaas, I. C., T. Rousing, C. Fossing, J. Hindhede, and J. T. Sörensen. 2003. Is lameness a welfare problem in dairy farms with automatic milking systems? Anim. Welf. 12:599-603. 
Kujala, M., C. Schnier, J. Niemi, and T. Soveri. 2004. Occurrence of hoof diseases in dairy cattle in Finland. Pages 45-47 in Proc. 13th Int. Symp. and 5th Conf. Lameness in Ruminants, Maribor, Slovenia. B. Zemljic, ed. http://www.ruminantlameness.com/end/ proceedings2004.pdf

Magee, D. R., and R. D. Boyle. 2002. Detecting lameness using "resampling condensation" and "multi-stream cyclic hidden Markov models." Image Vis. Comput. 20:581-594.

Neveux, S., D. M. Weary, J. Rushen, M. A. G. von Keyserlingk, and A. M. de Passillé. 2006. Hoof discomfort changes how dairy cattle distribute their body weight. J. Dairy Sci. 89:2503-2509.

O'Callaghan, K. A. O., P. J. Cripps, D. Y. Downham, and R. D. Murray. 2003. Subjective and objective assessment of pain and discomfort due to lameness in dairy cattle. Anim. Welf. 12:605-610.

Pastell, M., M. Hautala, V. Poikalainen, J. Praks, I. Veermäe, M. Kujala, and J. Ahokas. 2005. Automatic observation of cow leg health using load sensors. Comput. Electron. Agric. (accepted)

Pastell, M., H. Takko, H. Gröhn, M. Hautala, V. Poikalainen, J. Praks, I. Veermäe, M. Kujala, and J. Ahokas. 2006. Assessing cows' welfare: Weighing the cow in a milking robot. Biosyst. Eng. 93:81-87.

Rajkondawar, P. G., M. Liu, R. M. Dyer, N. K. Neerchal, U. Tasch, A. M. Lefcourt, B. Erez, and M. A. Varner. 2006. Comparison of models to identify lame cows based on gait and lesion scores, and limb movement variables. J. Dairy Sci. 89:4267-4275.

Rajkondawar, P. G., U. Tasch, A. M. Lefcourt, B. Erez, R. M. Dyer, and M. A. Varner. 2002. A system for identifying lameness in dairy cattle. Appl. Eng. Agric. 18:87-96.

Shan, Y., R. Zhao, G. Xua, H. M. Liebich, and Y. Zhang. 2002. Application of probabilistic neural network in the clinical diagnosis of cancers based on clinical chemistry data. Anal. Chim. Acta 471:77-86.

Specht, D. F. 1990. Probabilistic neural networks. Neural Netw. 3:109-118.

Sprecher, D. J., D. E. Hostetler, and J. B. Kaneene. 1997. A lameness scoring system that uses posture and gait to predict dairy cattle reproductive performance. Theriogenology 47:1179-1187.

Tasch, U., and P. G. Rajkondawar. 2004. The development of a SoftSeparator for a lameness diagnostic system. Comput. Electron. Agric. 44:239-245.

Van der Tol, P. P. J., S. S. van der Beek, J. H. M. Metz, E. N. Noordhuizen-Stassen, W. Back, C. R. Braam, and W. A. Weijs 2004. The effect of preventive trimming on weight bearing and force balance on the claws of dairy cattle. J. Dairy Sci. 87:1732-1738.

Visen, N. S., J. Paliwal, D. S. Jayas, and N. D. G. White. 2002. Specialist neural networks for cereal grain classification. Biosyst. Eng. 82:151-159.

Warnick, L. D., D. Janssen, C. L. Guard, and Y. T. Grohn. 2001. The effect of lameness on milk production in cows. J. Dairy Sci. 84:1988-1997.

Whay, H. R., D. C. J. Main, L. E. Green, and A. J. F. Webster. 2003. Assessment of the welfare of dairy cattle using animal-based measurements: direct observations and investigation of farm records. Vet. Rec. 153:197-202.

Winckler, C., and S. Willen. 2001. The reliability and repeatability of a lameness scoring system for use as an indicator of welfare in dairy cattle. Acta Agric. Scand. A 51(Suppl. 30):103-107.

Yang, Z., Z. Yang, W. Lu, R. G. Harrison, T. Eftestøl, and P. A. Steene. 2005. A probabilistic neural network as the predictive classifier of out-of-hospital defibrillation outcomes. Resuscitation 64:31-36. 